\title{
MODERNISATION OF EXISTING HOSPITALS
}

\author{
JACEK POPLATEK \\ Gdansk University of Technology, Poland
}

\begin{abstract}
Progress in medicine and development of medical technologies directly affect the evolution of methods for treating patients in hospitals. The main task of $19^{\text {th }}$-century hospitals was patient care and nursing, while the aim of hospitals today is to diagnose and treat patients effectively in the shortest time possible. The changes which are taking place in methods of treatment affect the functional-spatial layout of hospitals. This means, in the case of existing hospitals, that it is necessary to perform regular modernisations. Modernisation is connected with the functioning of every single hospital - assuming that medical equipment has to be replaced approximately every 10 years, it is possible that in the hospitals which were built only a dozen years ago it will be necessary to modernise certain units. As hospitals are among the buildings which are the most complex ones, both functionally and technologically, their modernisation is also a complicated and difficult process. Modernisation makes it necessary to take into consideration a number of requirements, which are sometimes difficult to reconcile, such as those connected with medical procedures, legal provisions and regulations, welfare of patients, as well as protection of historic substance in the case of historic hospitals. The oldest hospitals still functioning in Poland date back to the turn of the $20^{\text {th }}$ century. Hospitals built in the second half of the $20^{\text {th }}$ century constitute the second, largest group. This paper analyses the most significant features of hospitals, depending on their age, as well as the changes to which the most important hospital units are subjected. It discusses the possibilities and ways of modernising both historic hospitals and those which were built since the 1950s. The summary attempts to answer the question whether it is possible to find a universal methodology for modernising existing hospitals.

Keywords: hospital architecture, hospital modernisation.
\end{abstract}

\section{INTRODUCTION}

Modernisation is a cyclical process, connected with the functioning of every hospital. It is almost impossible to preserve the original functional-spatial layout during the entire period of a few dozen years when the hospital operates. The necessity of performing modernisation is influenced by a number of factors, which change in time. The most important ones of them are as follows:

1. the development of health technologies and methods of treatment, as well as the changes in organising work of medical personnel,

2. changes in disease incidence,

3. civilisational development of societies (and the expectations of patients and medical personnel connected with this development),

4. ageing of hospital equipment (technological equipment, installations, fittings),

5. changes and amendments of legal provisions.

The hospitals which are currently functioning in Poland can be divided into three groups: historic hospitals, built at the turn of the $20^{\text {th }}$ century; hospitals built from the 1950 s to the 1990s (constituting the largest group) and modern hospitals, built since the 1990s. This paper discusses the issues connected with modernising historic hospitals, dating back to the turn of the $20^{\text {th }}$ century and the hospitals built in the second half of that century.

\section{EUROPEAN HOSPITALS IN THE $19^{\mathrm{TH}}$ AND $20^{\mathrm{TH}}$ CENTURY}

The model of hospital which was developed two hundred years ago, was commonly applied throughout the century which followed. It was created due to the industrial revolution, which 
began in Europe at the start of the $19^{\text {th }}$ century. The development of industry led to rapid expansion of cities. Large communities, with low level of personal hygiene caused by lack of appropriate sanitation and hygiene equipment, brought about the deterioration of health among city inhabitants, and created conditions suitable for spread of epidemics and contagious diseases. The pollution of natural environment, non-existent before, was another result of industrial development. The hospitals existing at the time, old and overcrowded, were battling with the plague of health care-acquired infections and high rate of mortality. The doctors were aware of the fact that there is a direct connection between the high mortality rate and the sanitation-hygienic conditions in hospitals. Both doctors and architects pointed at the necessity of ventilating and lighting the patients' rooms, as well as of applying clear layouts of internal communication, which would limit transmission of infections. First and foremost, however, it was necessary to resign from placing all hospital wards in one building, with a square-shaped or cross-shaped plan, which were then considered to be the most optimal ones. It was therefore suggested that hospitals should be decentralised by locating individual wards in separate buildings. That was how the concept of pavilion layout, still in use at the beginning of the $20^{\text {th }}$ century, was developed [1].

The departure from the idea of integrated hospitals, where all patients were treated together, including those suffering from contagious diseases, made it possible to begin the fight against health-care acquired infections. The discoveries within the field of medical science, such as hand disinfection with calcium chloride during treatments (since 1847), disinfection with the use of carbolic acid sprayed in the course of treatments and surgeries (since 1867) and sterilisation of instruments with steam (since 1887) also contributed to the process of eliminating infections. The introduction of modern aseptic rules resulted in the decrease in postoperative mortality by several dozen percent.

In the $20^{\text {th }}$ century there was development of surgical techniques, thanks to more extensive knowledge of human physiology, as well as of diagnostic methods, the latter made possible by inventions in the areas of technology and medical sciences. Roentgenography - one of the basic diagnostic tests, consisting in recording of a two-dimensional image created when a beam of X-rays passes through organs, appeared at the beginning of the $20^{\text {th }}$ century. Ultrasonography - a diagnostic method using ultrasonic waves, has been applied since the 1950s. Further diagnostic methods which came into use in the 1970s include computer tomography, which allows for obtaining tomographic images (cross-sections) of examined objects and magnetic resonance imaging - a method of medical imaging (tomography), which makes it possible to obtain an image of the object interior.

The introduction of modern diagnostics and the development of surgical techniques influenced the form and functions of hospitals - both the functional layout and the form of hospitals evolved. There was a return to integrated hospitals, where all medical specialities were brought together. The division between diagnostic-treatment units and multi-bed wards, connected with patient care, was developed. The form of hospitals usually constituted a combination of a compact 2- or 3-storey basis (the so-called "wide foot"), where diagnostictreatment units were located, and a high-rise, hotel-like part, with individual nursing wards (Fig. 1).

\section{PATIENTS IN HOSPITALS}

The changes which occurred in shaping the function and form of hospitals resulted from medical procedures and treatment techniques applied at the time, as well as from the current level of medical technologies. The approach to patients was changing together with the development of diagnostics and treatment possibilities. This approach was not uniform 

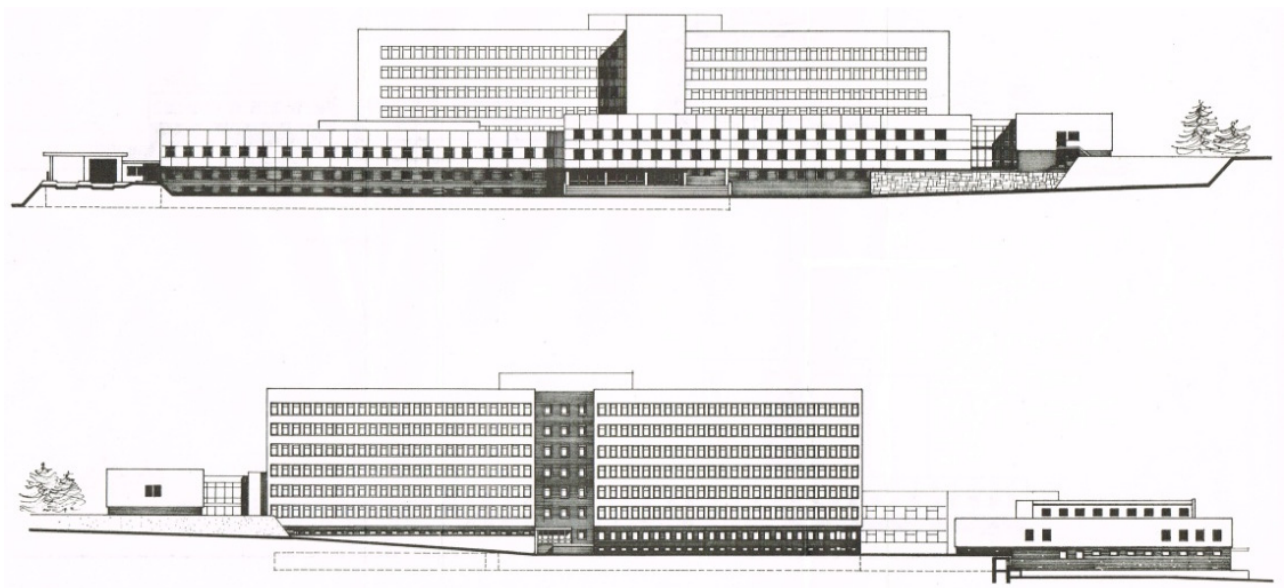

Figure 1: Form of the hospital from the second half of the $20^{\text {th }}$ century. Design of Regional Hospital in Rawa Mazowiecka by arch. H. Oska, façade drawing by E. Raczkowska. (Source: Biuletyn Informacyjny Budownictwa Sluzby Zdrowia, 2(86), 1989.)

throughout the discussed period of time (i.e. in the $19^{\text {th }}$ and $20^{\text {th }}$ centuries). The conditions for patients' stay in hospitals were taken into consideration when the pavilion layout was introduced. Such factors as locating the hospital in green areas, making sure that patients' rooms were sunny, as well as appropriate fitting-out of hospital interiors, which allowed for proper ventilation, limiting the number of people in rooms, increasing the comfort of patients' stay and improving sanitation-hygienic conditions, were regarded as facilitators of treatment. Patients in hospitals were treated as subjects, as it was understood that their good mental condition supports the therapy.

The situation changed in the first half of the $20^{\text {th }}$ century, together with the development in diagnostics and treatment; patients were treated as objects, subjected to certain medical procedures. That resulted in higher efficiency of treatment and elimination of health-care acquired infection threats. On the other hand, it negatively affected patients' minds, as they did not understand the actions undertaken by medical personnel. Medicalisation of treatment procedures led, in the 1970s, to protests for humanisation of hospitals. The problem was best visible in obstetrics and labour wards, where women in labour were subjected to medical "processing", and deprived of continuous contact with their newborn children and family members [2].

Currently, both doctors and architects clearly perceive that hospitals should combine various, sometimes contradictory functions. They have to allow for effective and, if possible, prompt diagnosing and treatment of patients, at the same time ensuring their mental welfare. It is also important to care for the work comfort of medical personnel, since it affects the personnel-patient relations.

The so-called Evidence Based Design (EBD), which imposes on architects and interior designers the obligation to base their work not only on knowledge, binding legal provisions and industry standards, but also on experience (not only their own) and results of scientific research, has become increasingly popular during the last decade, with regard to 
designing health care facilities. The aim of EBD is to create hospital space which would ensure well-being of two most important groups of hospital users -namely the patients and medical personnel [3], [4].

\section{MAIN HOSPITAL UNITS AND DIRECTION OF THEIR DEVELOPMENT}

The above-mentioned Evidence Based Design is applied not only in designing new health care facilities, but also in their modernisation. The existing and functioning hospitals, regardless of their age, should comply with current requirements. The priorities of hospital modernisation are varied, depending on the unit which is subjected to it; there are different priorities for diagnostic-treatment units and for nursing wards.

\subsection{Diagnostic-treatment units}

The diagnostic-treatment units are this part of hospitals which has undergone the most significant changes over the past few decades. The technological development has been providing doctors with better equipment which, in turn, influences the methods of treatment - the existing ones are changed and new ones, hitherto unknown, are introduced. It is assumed that medical equipment should be replaced approximately every 10 years. Replacement of equipment, as well as the introduction of new treatment methods are connected with the necessity to adjust the functional-spatial layout. The design experience shows that changes in the functional-spatial layout usually require obtaining additional space (Fig. 2).

What is more, the diagnostic-treatment units are characterised by the highest level of technical equipment saturation, the necessity to maintain absolute aseptics and appropriate air parameters, to monitor the patients' condition, etc. The postulates of hospital humanisation and well-being of patients are of secondary importance in diagnostic-treatment units; the highest possible efficiency of treatment is the priority, and the way in which the units function is subordinated to it.
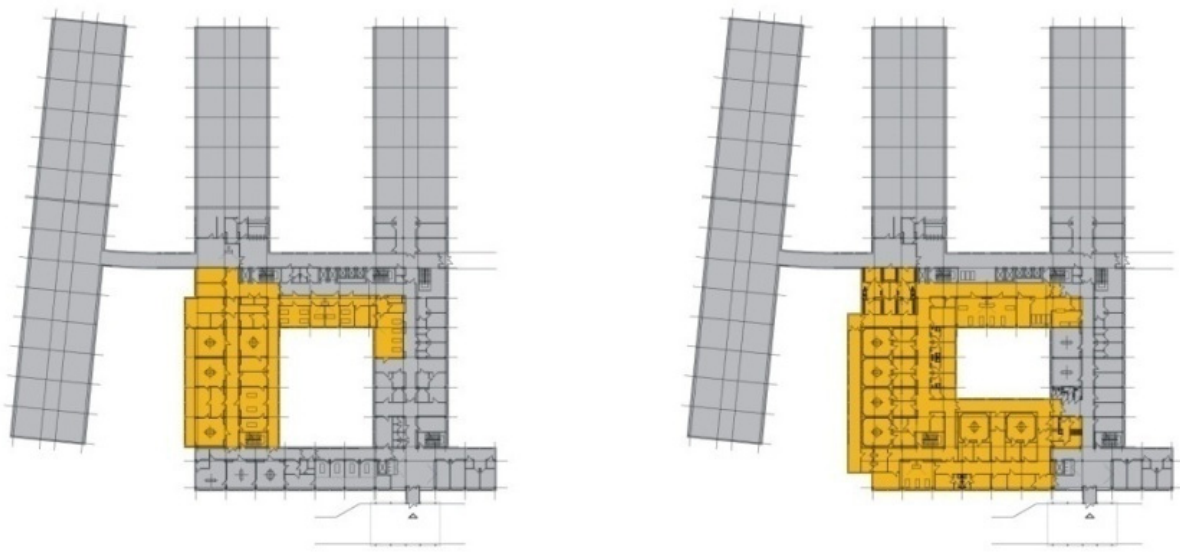

Figure 2: Operating theatre in Regional Hospital from the 1970s in Wejherowo; on the left: view in accordance with the original design from 1972 by arch. J. Szanajca, R. Borkowski; on the right: conceptual design of modernisation. After the modernisation the area of operating theatre was increased by approximately $80 \%$. (Source: author's own elaboration.) 


\subsection{Nursing wards}

Today the average time of patients' stay in hospitals is shorter than in the 1980s, and this trend still continues. This is beneficial not only to the economics of hospital functioning, but also to patients' mental welfare [5]. However, the treatment is still connected with a hospital stay in nursing wards. The changes which nursing wards were subjected to over the last fifty years are not directly connected to technological development. In this part of hospitals treatment procedures were not of paramount importance and the changes which occurred consisted mostly in ensuring that patients are comfortable. Multi-bed rooms were changed into smaller ones, usually double and, more rarely, single, with en-suite bathrooms. Double rooms have an advantage over single ones - they allow for ensuring comfort of stay and, at the same time, patients are able to support each other by way of conversation. The postulates for hospital humanisation are still valid in nursing wards. Patients' well-being, which facilitates therapy, is influenced by good relations with personnel, unlimited contact with persons related to them (family members) and the quality of hospital space - colours, materials, acoustics, ventilation, lighting, etc. Ensuring aseptic conditions is also important, but much easier to achieve than in diagnostic-treatment units.

\section{MODERNISATION OF EXISTING HOSPITALS}

The lifespan of hospitals recommended today is 50 years. After this time, a hospital should be demolished and a new one constructed in its place. Such approach is justified, taking into consideration the issue of health-care acquired infections, caused by mutating bacteria, microorganisms and viruses. Are they hazardous to health of both patients and medical personnel, and is it possible to remove this hazard during renovation or modernisation? The opinions are divided. Medical communities (in particular experts on contagious diseases) opt for a radical action (demolition of an old hospital and construction of a new one), while the compromise solution (i.e. modernisation, reconstruction or, possibly, change of function) is supported by economic reasons and, in the case of historic hospitals, by heritage monuments protection community [6].

Hospitals built in the second half of the $20^{\text {th }}$ century are still functioning in most European countries, despite the fact that they have been operating for more than 50 years. Much older hospitals, dating back to the turn of the $20^{\text {th }}$ century, are also functioning in Poland. This is mostly due to economic reasons. On the one hand, the cost of hospital modernisation (particularly in the case of historic hospitals) may be higher than building a new hospital. On the other hand, modernisation may be limited to individual units and performed in stages, which allows for distribution of expenses in time and is economically justified. Staging of modernisation activities is advisable for another reason - it allows for uninterrupted functioning of a hospital, which is not possible when the entire hospital is subjected to onestage modernisation.

It is therefore extremely important to plan modernisation appropriately, taking into consideration the hospital as a whole, and avoiding fragmentary design activities. Modernisation should be preceded by a conceptual design for modernisation of the entire hospital (or its bigger part), even if only one unit is to be modernised. Fragmentary modernisation works may result in deterioration of hospital functioning; they may also impair or render impossible future modernisation or hospital extension works.

In order to make hospital modernisation effective, it is necessary to fulfil certain conditions, the first of which is connected with hospital location. Location in a convenient, central, well-connected place on the city map is a key argument indicating that modernisation is justified. The size of the plot and additional space allowing for hospital extension (and, 
possibly, further extensions in long-time perspective) are also important. Fulfilment of the above-mentioned conditions constitute the basis for making a decision concerning modernisation, regardless of the age of the hospital and its functioning time.

\subsection{Modernisation of historic hospitals}

The main function of historic hospitals, dating back to the turn of the $20^{\text {th }}$ century, was to take care of patients, hence the majority of the hospital area (over $80 \%$ ) was occupied by multi-bed wards. In large city hospitals and university hospitals, they were usually located in separate buildings (within the pavilion layout). The pavilion layout had a lot of disadvantages, such as the necessity to go outside in order to pass to another unit, the fact that individual buildings were located at different heights (due to natural topography), as well as the necessity to have hospital facilities in each of the pavilions. However, the pavilion layout allows for introducing new cubature between the existing buildings in the course of modernisation. It is particularly important when diagnostic-treatment units are modernised (for example the operating theatre) as, due to extensive spatial and technological requirements, it is difficult to fit them into a historic building with traditional structural layout, limited span and long, usually three-row, plan. In the case of modernising a diagnostic-treatment unit (including, for example, an operating theatre) the extension, appropriately connected to the existing buildings, is usually the most optimal solution (Fig. 3).

Modernisation of nursing wards in hospitals dating back to the turn of the $20^{\text {th }}$ century are not more difficult, with regard to correction of functional solutions and adjusting the building to current requirements and regulations, than in the case of newer hospitals.

A design for hospital modernisation requires from its authors more knowledge and experience than in the situation when a hospital is designed from scratch. In the case of modernisation an architect, apart from the knowledge necessary to design health care facilities, must possess the skill to make compromise decisions, as modernisation often involves conditions and limitations which are difficult to reconcile. In modernisation of historic hospitals there is an additional difficulty, namely the necessity to design in compliance with monument-protection requirements, ensuring that historic buildings will be preserved in the state as unaltered as possible. In the case of hospitals, i.e. buildings with complex functional layout and the highest degree of technological saturation, it is a very

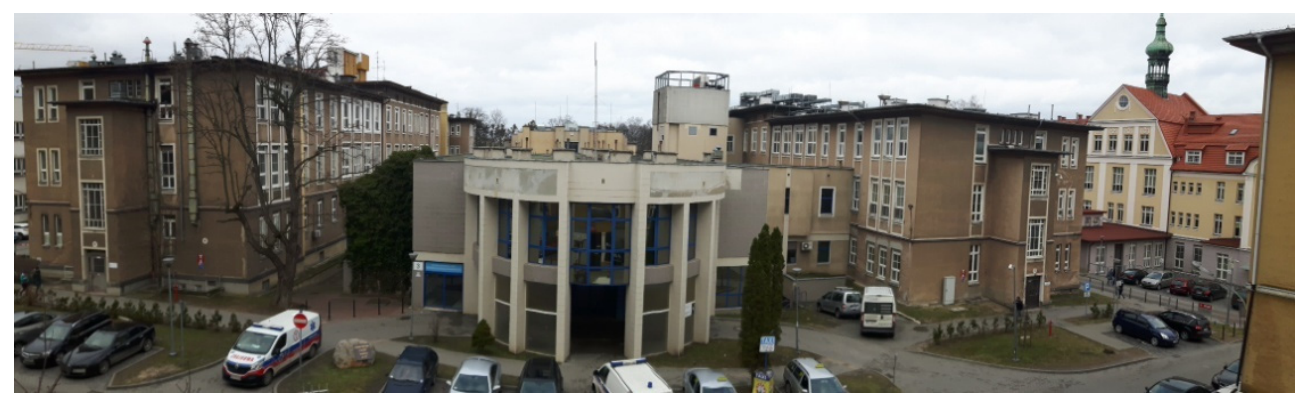

Figure 3: Hospital of Gdansk Medical University from the beginning of the $20^{\text {th }}$ century, with pavilion layout. The building of cardiovascular surgery unit with operating theatre, built during modernisation in the 1990s, is visible between historic pavilions. Modernisation and extension design by arch. A. Kohnke. (Source: author's photograph.) 
difficult task. It is recommended to adopt an individual model of monument protection in each case, and to establish the limits of possible interference into the existing substance of a historic hospital. An important issue is to protect the historic structure of the building, retain its functional layout (if possible), as well as to secure all its historic elements and architectural details [7].

\subsection{Modernisation of hospitals from the second half of the $20^{\text {th }}$ century}

Newer hospitals, built since the 1950s are more open to transformations. This results mostly from their clear structural layout, based on a column grid, which allows for fairly easy changes in the functional-spatial layout and corrections in technical and technological installations. It is particularly important with regard to modernising diagnostic-treatment units, where the necessary functional modifications are the most substantial. Also in the case of hospitals from the $2^{\text {nd }}$ half of the $20^{\text {th }}$ century, even though their structural layout is more open to change, modernisation must usually be combined with smaller or larger extension.

In case of extension, modular construction may form an alternative to the reinforced concrete frame technology. Some hospitals in Europe have been constructed with the use of modular technology. Its undeniable advantages include short realisation time (due to the fact that the majority of elements are prefabricated) and flexibility in shaping the functional layout. Modular objects (in this case container ones) may also be applied as temporary ones during modernisation of a hospital, so that its functioning is not interrupted [8].

\section{CONCLUSIONS}

Both groups of hospitals discussed in this article are characterised by openness to modernisation. In historic hospitals, due to the necessity of undertaking preservation works, the modernisation process is made more difficult and more expensive - both at the stage of design works and investment preparations, as well as in the course of project realisation, yet it is not rendered impossible.

Should hospitals be modernised, then, and if so, what is the time period when undertaking modernisation is justified? The answer is affirmative, but requires some comments. Hospitals are among these public utility buildings which are most complex with regard to technology and the most expensive, hence their lifespan has to be established, due to economic reasons. Assuming that a hospital is going to function for 50 years, it may be supposed that, during this time, it will undergo even a few necessary modernisations. It results from the pace at which medical technologies and treatment methods are developing, as well as from the necessity to replace medical equipment cyclically, approximately every 10 years. What will happen to a hospital after the assumed functioning time has passed?

There is no universal solution which could be applied in every case. Historic hospitals, dating back to the turn of the $20^{\text {th }}$ century, belong to important architectural heritage, and should be protected. If the hospital location and the size of the plot allow for modernisation and extension, they should also retain their function. Unfortunately, the necessity to preserve and secure the historic tissue of historic hospitals often deters investors, who prefer easier solutions, i.e. adaptation of modern buildings or construction of new ones. Passage of time is not always beneficial to historic hospitals, which may result in slow destruction of historic health care architecture.

Hospitals built since the 1950s are more open to modernisation works; it is not obvious, however, that they should be modernised after functioning for a few dozen years. The architecture of hospitals built in the second half of the $20^{\text {th }}$ century was subordinated to function, and usually did not have any interesting, distinguishing characteristics, which 
should be protected. Hence the undertaken actions are often dependent on economic conditions. In the most affluent European countries the best solution may be to demolish the existing hospital and build a new one. In less wealthy countries, such as Poland, due to limited financial capacity of the public health care sector, the most common possible choice will be modernisation, with the assumption that its realisation should be staged.

\section{REFERENCES}

[1] Jachowicz, B., Poglady na racjonalne planowanie i budowe szpitali w drugiej polowie XIX stulecia. Szpitalnictwo Polskie, II(3), 142 pp., Warszawa 1963.

[2] Poplatek, J. \& Bąkowski, J., Humanizacja traktu porodowego - teoria i praktyka. Zeszyty naukowe Politechniki Slaskiej - Architektura a zdrowie, 53, pp. 185-194, Gliwice 2013.

[3] Hamilton, D.K., The four levels of evidence-based practice. Healthcare Design, 3(4), pp. 18-26, 2003.

[4] Cochrane, A.L., Effectiveness and Efficiency: Random Reflections on Health Services, Nuffield Provincial Hospitals Trust, Vol. 900574178: London 1972. Reprint: Nuffield Trust by the Royal Society of Medicine Press: London, 1999.

[5] Malkin, J., Medical and Dental Space Planning: A Comprehensive Guide to Design, Equipment, and Clinical Procedures, John Wiley \& Sons, 2002.

[6] Waszczyszyn, E., Examples of strategies of preservation activities in historic complexes of hospital architecture, Technical Transactions - Architecture, 6-A, pp. 251-272, Kraków 2015.

[7] Gerber, P., Problemy modernizacji zabytkowych szpitali. Wiadomości Konserwatorskie, 22, pp. 109-111, Warszawa 2007.

[8] Lukasik, M., Modular construction. An opportunity for existing buildings of polish health service? Housing Environment (Wydawnictwo Politechniki Krakowskiej), 14, pp. 148-157, Kraków 2015. 